\title{
An Investigation into the Implementation Processes of Ghana's Primary Health Care Strategy: The Community-Based Health Planning and Services Programme.
}

Matthew Kwame Edusei ( $\sim$ kwameedusei@gmail.com )

Premier Medical Solutions (Gh) Ltd https://orcid.org/0000-0003-1492-5795

Kofi Bobi Barimah

Ghana Telecom University College: Ghana Technology University College

Samuel Kwadwo Asibuo

MountCrest University College

Research

Keywords: Implementation, Community-based Health Planning and Services, Ga East and West Municipalities, Exploratory research

Posted Date: February 22nd, 2021

DOl: https://doi.org/10.21203/rs.3.rs-168499/v1

License: (c) (1) This work is licensed under a Creative Commons Attribution 4.0 International License.

Read Full License 
TITLE OF PAPER:

AN INVESTIGATION INTO THE IMPLEMENTATION PROCESSES

OF GHANA'S PRIMARY HEALTH CARE STRATEGY: THE

COMMUNITY-BASED HEALTH PLANNING AND SERVICES

\section{PROGRAMME.}

DR. MATTHEW KWAME EDUSEI ${ }^{1}$, DR. KOFI BOBI BARIMAH ${ }^{2} \&$ DR. $^{2}$ SAMUEL K. ASIBUO ${ }^{3}$

1. Private medical practitioner and adjunct lecturer (kwameedusei@gmail.com)

2. Chief Executive Officer, Centre for Plant Medicine Research, Mampong (kbarimah@gtuc.edu.gh)

3. Dean of Business School, Mountcrest University College, Accra.

Corresponding author: Dr. Matthew Kwame Edusei (kwameedusei@gmail.com)

\section{ABSTRACT}

Background: Ghana has adopted the community-based health planning and services (CHPS) programme as the public health strategy for meeting its universal health goals.

The programme is facing implementation challenges that are affecting its expansion within the communities. This research was undertaken to examine the implementation processes of CHPS and suggest solutions to improve its scaling-up within the communities.

Method: An exploratory research design was used with a mixed method approach that involved the testing of a hypothesis. 
Results: The study found that in places with on-going CHPS programmes, there is statistically significant $(p<0.001)$ evidence that the implementation processes are not flawed. However, the district assemblies were selective in the allocation of CHPS zones within the communities.

Conclusion: Chieftaincy conflicts within the communities are impeding the community entry aspect of the CHPS policy implementation processes and needs to be addressed by policy makers in the relevant government agencies.

Keywords: Implementation, Community-based Health Planning and Services, Ga East and West Municipalities, Exploratory research.

\section{Introduction}

The World Health Report of 2013 defined universal health systems along three parameters: service provision, number of populations served and financial sustainability of healthcare services. The World Health Organization (WHO) recommends the implementation of primary health care (PHC) strategies as a means of meeting the service provision and population coverage aspects of universal health systems (WHR 2008). Ghana has adopted the community-based health planning and services (CHPS) programme, launched in year 2000, as the primary health care model to achieve the first two objectives of universal health systems with the national health insurance scheme (NHIS) taking up the financial arm (MOH 2016).

The community-based health planning and services (CHPS) concept was introduced into the Ghanaian healthcare delivery system with the objectives of improving equity and access to basic healthcare services; improving efficiency and responsiveness to 
client needs and developing effective intersectoral collaboration on health issues at the district level (Adongo et al. 2014). The CHPS programme was seen as a means of improving health service delivery as well as engaging and sustaining the interest of community members in taking charge of their healthcare needs. Eight years after its launching, the programme had been implemented in all of Ghana's districts. However, by the year 2009, it had become evident that implementation challenges were affecting the scaling-up of the programme, and CHPS, as it was originally envisioned, was reaching only $12 \%$ of Ghana's households (Binka et al. 2009). In almost all parts of the country, expansion of the programme had either stalled or was incomplete. The challenges included lack of office accommodation / non-availability of CHPS compounds, poor deployment and placement of community health officers (CHOs) in the communities, lack of logistics for CHPS and lack of budgetary support for the implementation processes. Moreover, fidelity to the original CHPS model, developed at Navrongo, had dissipated over time (Nyonator et al. 2005; Krumholz et al. 2014).

If successfully implemented, the CHPS programme would help address a lot of the healthcare delivery challenges Ghana has faced since independence. The country lacks the requisite number of trained medical doctors that are needed for the healthcare delivery system, which often result in delays in seeking care. Also, large volumes of patient load often result in staff fatigue and low morale, which is associated with poor staff attitude, patience dissatisfaction and cases of medical negligence (Pienaar 2016). Studies have shown that people often migrate from the rural areas to the cities in search of medical care, since most of the clinical healthcare facilities are located in the larger towns and cities (McCormack et al. 2017). A well-functioning CHPS programme 
would, therefore, not only save the country money, but will also stem the perineal ruralurban migration in the country.

For Ghana to achieve universal health coverage, it is imperative that the CHPS programme becomes successful. Evaluating such success would depend on the availability of empirical data that supports the anecdotal evidence of the achievements of the CHPS programme. The data from this study exposed the strengths and weaknesses of the implementation processes, which would help the district managers recognize areas that need improvement. Policy makers, especially those in the health and allied ministries, are expected to use the data from this study to formulate better CHPS and other health implementation policies for the country. Furthermore, the study is expected to help the Ghana Health Service (GHS) to fashion out better healthcare delivery services to the rural and the peri-urban communities. Finally, this study opens up new research areas in the CHPS concept of healthcare delivery in Ghana and elsewhere. This study examined the implementation processes of the CHPS programme by the Ga East and Ga West municipal assemblies with the objective of identifying the constraining factors affecting its expansion within the communities.

\section{Methods}

\section{Ethics statement}

After satisfying the protocol requirements for the study, ethical approval was obtained from the Ghana Health Service Ethics Committee. Written informed consent was sought from all respondents before taking part in the study and also before interviews were recorded. No oral consent was accepted for this study. Personal identifiers and 
locator information were not collected and any identifying information accidentally mentioned was removed from the text prior to data analysis.

\section{Research design}

The study examined a hypothesis, based on Binka et al, that the CHPS policy implementation process was flawed. An exploratory study was designed for this research with a mixed methods approach involving qualitative and quantitative elements. The quantitative method was chosen because it was deemed useful in providing an objective assessment of the CHPS programme and also to add to the literature on CHPS.

\section{The study area}

Two districts within the Greater Accra region were chosen for the study: the Ga West and the Ga East municipal assemblies. The two districts were selected for this study because they are among the oldest local government units in the Greater Accra Region and are therefore endowed with well-established district structures. As well as having functioning CHPS programmes, the two also have long-term experience in district health administration. Furthermore, the selected districts have both rural and urban features, which allowed the study to benefit from an enriched understanding of the interactive processes that evolve between decentralized structures and communities in both the rural and urban settings with respect to health care delivery.

The Ga West municipal assembly is peri-urban in nature, occupies a land surface area of $299.578 \mathrm{Km}^{2}$, had a population of 219,788 in the 2010 census and shares boundaries 
with five districts (Figure 1). The Ga East municipal assembly is in the northern part of the Greater Accra Region, covers a land surface area of $85.7 \mathrm{Km}^{2}$ and had a population of 147,742 in 2010 (Ghana Statistical Service 2014). Ga East district is sub-divided into two zones: the Abokobi Zonal Council and the Dome Zonal Council. It shares boundaries with four districts (Figure 1).

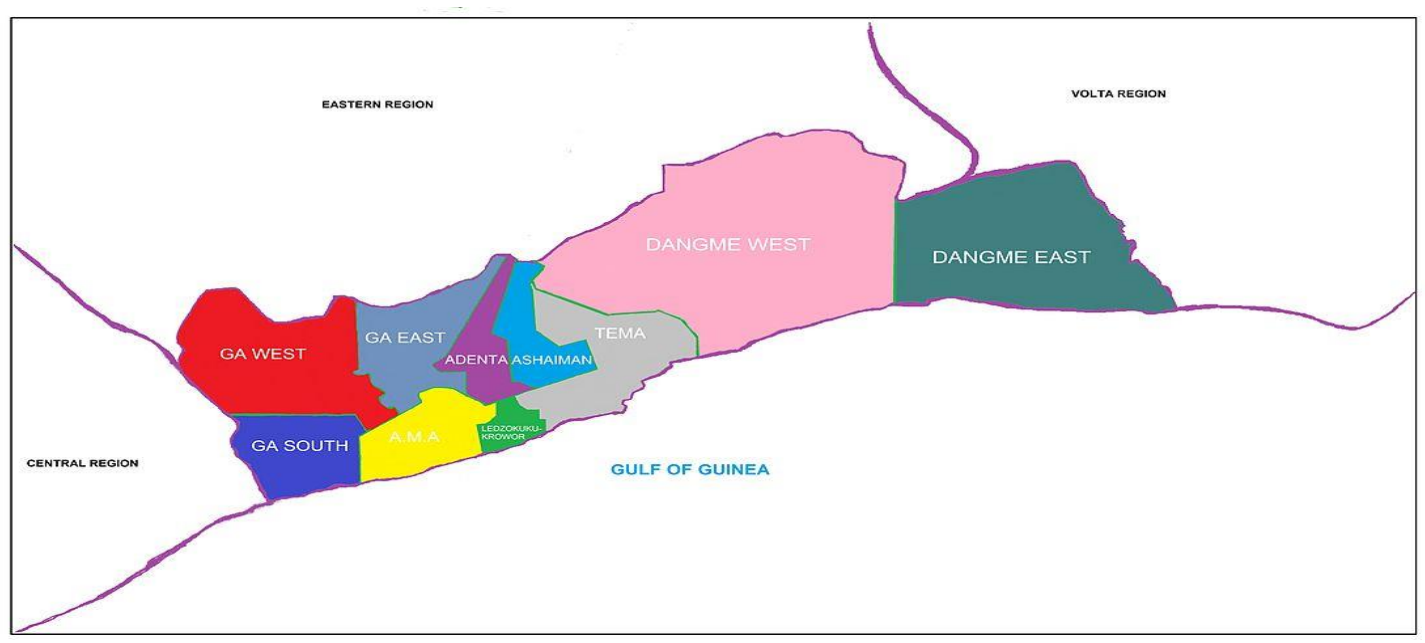

Fig:1 Districts in the Greater Accra Region showing locations of Ga East and Ga West

Source: www.ghanadistricts.com (Retrieved on $5^{\text {th }}$ March 2018)

\section{Sampling technique and data collection procedures}

With a study population of 640 , the sample size was determined to be 240 at $95 \%$ confidence level using a digital sample size calculator, the Creative Research Systems Survey software [Version 11]. The study employed two sampling techniques. A purposive sampling technique was first used to select key informants who are knowledgeable about the history and the implementation processes of the CHPS programme. A simple random sampling method was then used to select respondents from among the purposefully selected participants. Three instruments were used for 
data collection: a semi-structured questionnaire, in-depth interviews and focus-group discussions.

A six-point Likert-scale type questionnaire ranging from (1=strongly agree to $6=$ strongly disagree) was administered to the selected participants. Two hundred and forty (240) such questionnaires were distributed among the study participants out of which $196(81.7 \%)$ were returned. Following this, five (5) individuals from each of the municipalities were randomly selected from among those who responded to the questionnaire for in-depth interviews (IDIs). Seven (7) randomly selected individuals from within the study participants of each of the districts were used for a focus-group discussion (FGD). All qualitative data were audiotaped using digital audio-recorders.

\section{Analytical procedures}

The study examined the hypothesis that the CHPS policy implementation processes were flawed by using five variables: the extent of CHPS marketing in the communities; fidelity of the implementation processes to the 15 policy steps; roles played by the traditional authorities (TAs) in the implementation processes; the extent of community participation in the implementation processes and the district assemblies' (DAs) management of the implementation processes.

The main emerging themes in all the transcriptions from the recorded interviews were identified and coded into "NVivo 10" software package for qualitative data analysis. The study explored the distribution of socio-demographic/economic factors using frequencies and percent-frequencies. Bivariate analysis, based on Chi-square test of independence and the Fishers Exact test, were conducted to determine the association 
between each of the socio-demographic factors and the prevailing condition of the CHPS policy implementation processes. The null hypothesis was tested using onesample t-test after the distribution has satisfied the normality test. All the statistical analyses were performed using Stata version 14 (StataCorp, College Station; Texas, USA) and p-value less than 0.05 was considered statistically significant. The quantitative data was presented in the form of tables (frequency tables) and charts for easy interpretation and analysis.

\section{Results}

\section{a. Qualitative results}

\section{Marketing of CHPS}

On the question of how well the CHPS programme was marketed in the communities, the general consensus was that the programme was not well advertised. Majority of the respondents were of the view that previous marketing of the programme was better compared to the present.

"The CHPS programme was better advertised in the past. Nowadays, we don't hear of the district assembly (DA) going round the communities informing people about CHPS. Sometimes the DA even sets up a CHPS zone without informing the people and then we the committee members have to be answering the questions they should be answering”. (Community Health Management Committee Member [CHMC], IDI) 


\section{Fidelity to the CHPS policy implementation steps}

Respondents were of the view that the district assembly tried, but failed to follow the 15-implementation steps in the CHPS policy document. They were unanimous that the implementation steps were cumbersome and time-consuming. Some respondents also felt the implementation steps were not well-aligned and sometimes created confusion during the implementation process.

"The DA tried to follow the steps in the CHPS policy document. The 15 steps are too long and cumbersome and not well-aligned. For instance, I believe step 7 (compilation of community profile) should either precede or be part of step 1 (planning by the DHMT). The steps should be shortened to make the process easier to follow." (Assembly Member, IDI)

\section{Role played by the traditional authorities (TAs)}

There were mixed responses to the roles played by the traditional authorities in the communities with respect to the implementation process. Whereas some respondents thought that the chiefs, in particular, did not play any meaningful role with the process, others were of the strong view that the opinion leaders played key roles. Some contended that the chiefs did not want to be seen as hijacking the process, hence their support was minimised in the public view.

"The chiefs were supportive of the programme, but they didn't want to be seen as the ones in charge so they provide support on the quiet. They are the ones who summon the people for durbars on CHPS activities. Some even provided office space and accommodation for CHOs in the CHPS zones." (Opinion Leader, FGD) 


\section{Community participation}

Respondents agreed that the community members played a satisfactory role in the implementation process, especially in the rural areas. Some, however, were of the view that community participation in the urban and peri-urban areas was not encouraging.

"The community members offered their skills and labour to support the CHPS programme. This was especially so in the rural communities. Support from the urban and peri-urban areas was challenging as the people complained of not having time for CHPS activities." (CHMC, FGD)

\section{District assembly management of the implementation process}

There was overwhelming agreement that the district assemblies (DAs) managed the implementation processes quite well. There were, however, a few dissenting views from respondents who thought the assembly could have done better by involving other stakeholders within the communities.

"The DAs are managing the CHPS programme quite well considering the scanty resources at their disposal. There are many challenges with CHPS including lack of office space and logistics, but the assemblies are coping with the situation, though there is room for improvement. If the community members involved themselves as well as they should with the process, we all could have achieved a lot with CHPS. On a scale of 1-10, I would score the district assemblies 8 for their management of the process." (Opinion Leader, IDI) 


\section{b. Quantitative results}

\section{Socio-demographic characteristics of study participants}

One hundred and ninety-six participants took part in the study with the Ga West providing 102 (52\%) and Ga East contributing 94 (48\%). Female participants constituted 124 (63\%) with males forming 72 (37\%). The participants aged between 28-and-60 years and most of them (58\%) were married with $74 \%$ having at least one child. The educational level of the participants was high with $95 \%$ having had formal education out of which about half (50.5\%) have had tertiary education. About a quarter of the participants (28\%) were self-employed and their income levels ranged between GHC 600 (\$115) and GHC 1,500 (\$290) per month (Table 1).

\section{Table 1: Socio-demographic characteristics of study participants $(n=196)$}

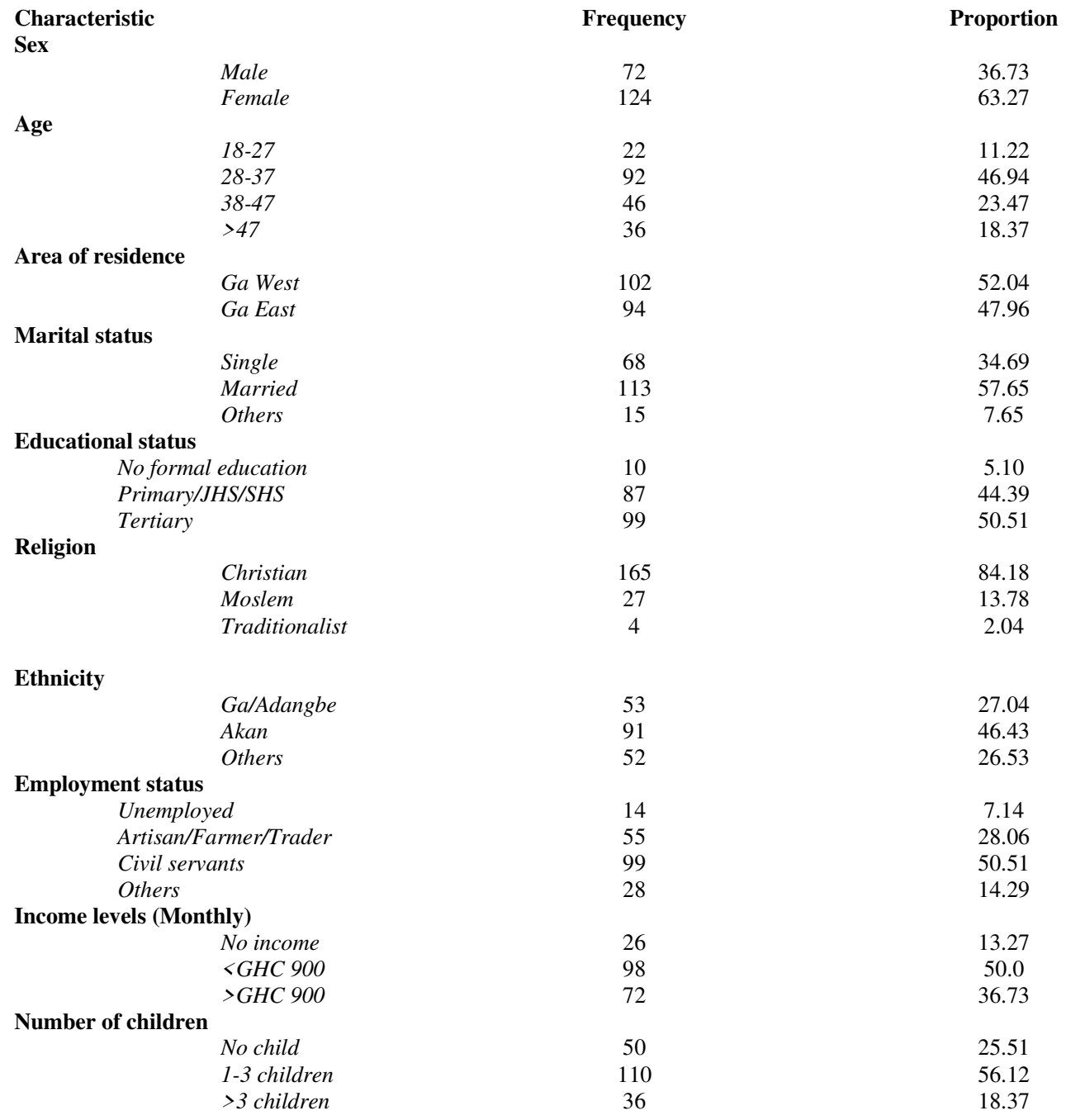




\section{Responses on the assessment of the CHPS programme}

On the question of the marketing of the CHPS programme within the communities, majority $(79.6 \%)$ of the respondents were of the opinion that the programme was not well-marketed. As to how well the implementation process focused on the milestones of the CHPS policy document, $62.2 \%$ of the respondents were of the view that the process did not follow the CHPS milestones. A significant minority of $37.8 \%$, however, disagreed. Only $41.8 \%$ of the respondents were of the opinion that the traditional authorities played any major role in the implementation processes. Majority (58.2\%) of the respondents were of the view that the traditional authorities did not play any major role in the implementation processes. However, majority of the respondents (61.2\%) were of the view that community participation in the implementation process was low. Nevertheless, there was overwhelming support for the district assemblies' management of the CHPS programme implementation processes with an $89.8 \%$ approval rating. The frequency distributions of the responses are highlighted in Table 2 and graphically presented in Figure 2.

Table 2: Responses to the CHPS policy implementation processes $(n=196)$

\begin{tabular}{|c|c|c|c|c|c|}
\hline \multicolumn{5}{|c|}{ Responses [n (\%)] } \\
\hline Variable & CHPS was & Implementation was & TAs played & Community & DAs managed \\
& well-marketed & not focused on CHPS & no major role & participation & the processes \\
& & milestones & in the process & was low & well \\
\hline Agree & $40(20.40)$ & $112(62.24)$ & $114(58.16)$ & $120(61.22)$ & $176(89.80)$ \\
Disagree & $156(79.80)$ & $74(37.76)$ & $82(41.84)$ & $76(38.78)$ & $20(10.20)$ \\
\hline
\end{tabular}




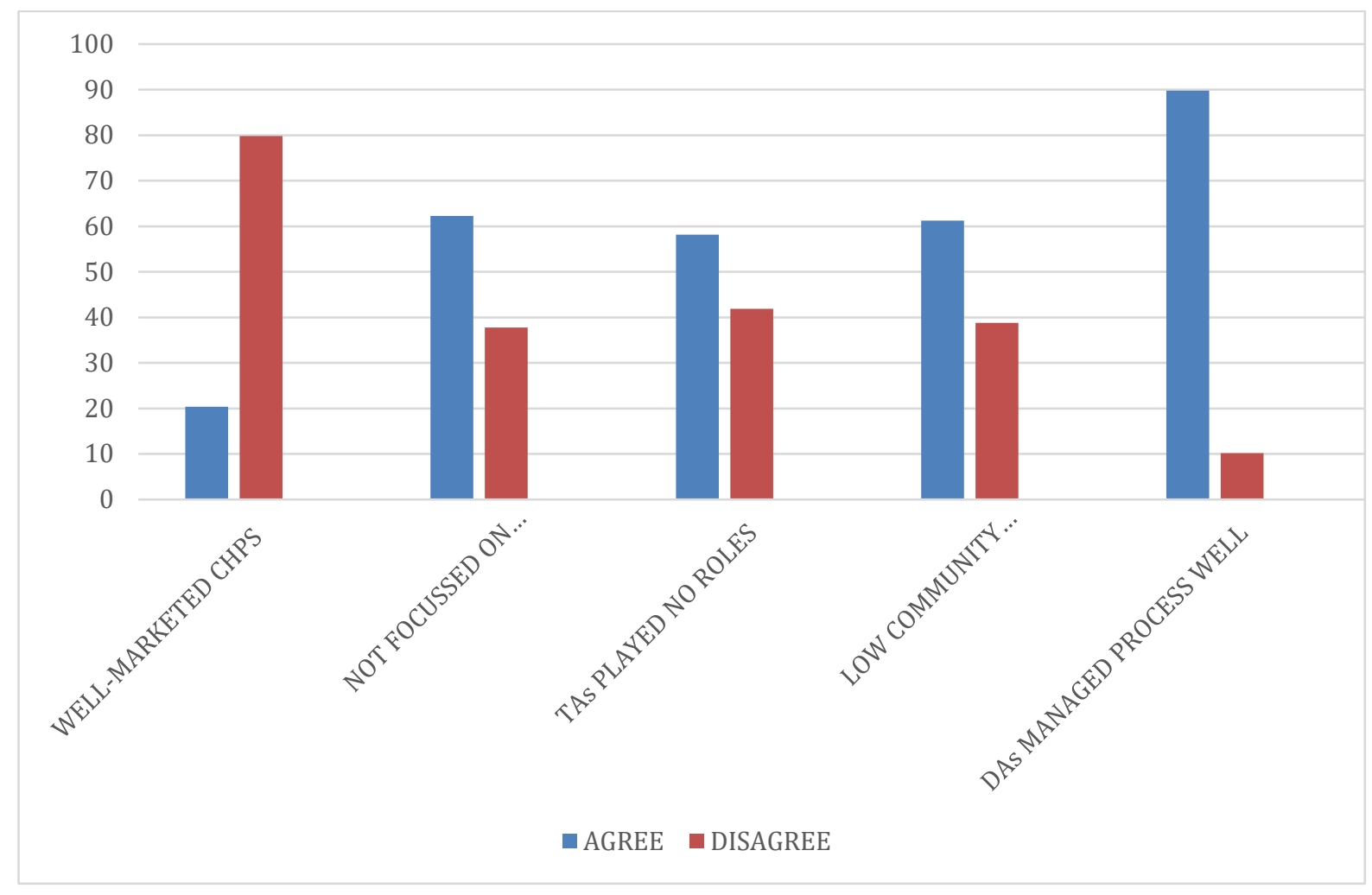

Fig. 2: Responses to the CHPS policy implementation processes

Statistical analysis of the quantitative data

Statistical analysis of the quantitative data indicated that the CHPS policy

implementation processes were not flawed, as indicated by 113 (57.6\%) of the study

participants (Table 3).

Table 3: Evaluation of the CHPS programme in Ga East and Ga West Municipal Assemblies.

\begin{tabular}{ccc}
\hline Management domain & Frequency & Proportion \\
\hline CHPS POLICY IMPLEMENTATION & & \\
Not flawed & 113 & 57.65 \\
Flawed & 83 & 42.35
\end{tabular}




\section{Results of hypothesis testing}

Based on the one sample t-test and the corresponding $p$-value, this study rejected the null hypothesis that the CHPS policy implementation processes were flawed $(\mathrm{p}<0.001)$. The results showed statistical evidence that the CHPS policy implementation processes were not flawed (Table 4).

Table 4:

Assessment of the performance of the CHPS programme in Ga East and West Municipal Assemblies

\begin{tabular}{llllll}
\hline Natural log variable & $H_{o}$ & Mean & SD & $95 \%$ CI & P-value
\end{tabular}

CHPS POLICY

IMPLEMENTATION

$\begin{array}{lllll} & \leq 1.03 & 1.16 & 0.24 & (1.12,1.19)\end{array}$

Note:

$\boldsymbol{H}_{\boldsymbol{o}}$ : Null hypothesis of population mean score pegged at the $25^{\text {th }}$ percentile value indicating that the implementation process was flawed.

SD: standard deviation. CI: confidence interval. *: $\mathrm{p}<0.05 . * *: \mathrm{p}<0.01 . * * *: \mathrm{p}<0.001$.

\section{Association between the socio-demographic characteristics and the flawlessness or otherwise of the CHPS policy implementation processes.}

Bivariate analysis using Fisher's exact test indicated that married people, those with high levels of education and people with children believe that the CHPS policy implementation processes were not flawed. On the other hand, the single, the selfemployed, the less educated and low-income earners were of the opinion that the processes were flawed. The results further showed that females and people less than 40 
years old (the youth) were less likely to see the processes as flawed compared to males and the elderly. The analysis also revealed that the most significant demographic characteristic associated with the flawlessness or otherwise of the CHPS policy implementation process is the educational level of the individual (Table 5).

Table 5: Association between the socio-demographic characteristics and the flawlessness or otherwise of the CHPS implementation process.

\section{CHPS Policy Implementation Process}

\section{Characteristic}

Gender:

$$
\text { Male }
$$

Female

Age:

$$
\begin{aligned}
& <40 \text { years } \\
& >40 \text { years }
\end{aligned}
$$

Marital status:

Educational status:

$$
\begin{aligned}
& \text { Single } \\
& \text { Married }
\end{aligned}
$$

Pre-tertiary

Tertiary

$$
\text { Self-employed }
$$

Civil servant

Income levels (Monthly):

$$
<\text { GHC } 900.00
$$

> GHC 900.00

Number of children:

$$
\begin{aligned}
& \text { Ga East } \\
& \text { Ga West }
\end{aligned}
$$

Employment status:

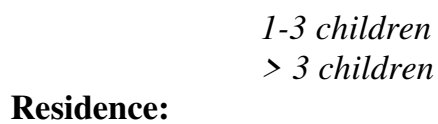

\section{Not Flawed}

n $(\%)$

35 (31.25)

77 (68.75)

69 (61.06)

44 (38.93)

33 (29.2)

72 (63.72)

$42(37.17)$

$68(60.18)$

$33(29.2)$

$60(53.1)$

$52(46.02)$

$50(44.25)$

$72(63.72)$

19 (16.81)

$49(43.36)$

$64(56.64)$
Flawed

n $(\%)$

36 (43.37)

$47(56.63)$

$45(54.22)$

38 (45.78)

35 (42.17)

$41(49.4)$

$45(54.22)$

$31(37.35)$

$22(26.51)$

39 (46.99)

$46(55.42)$

$22(26.51)$

$38(45.78)$

17 (20.48)

6.91

$0.032 *$

$52(62.65)$

$31(37.35)$

3.03

0.082

$4.03 \quad 0.258$

$4.14 \quad 0.127$

$2.26 \quad 0.521$

$7.45 \quad 0.024 *$

$.024^{*}$ $\gamma^{2} \quad P$-value

$11.20 \quad 0.004 * *$

$\mathbf{n}$ : frequency in each cell; $\%$ column proportion; $\gamma$ : Fisher's exact test; $*: p<0.05 ; * *: p<0.01$. 


\section{DISCUSSION}

The study found enough statistical evidence to conclude that the CHPS policy implementation processes were not flawed $(\mathrm{p}<0.001)$. However, the process faces challenges that are making it less effective than expected. The CHPS implementation process centers on community participation, with the chiefs and the traditional leaders of the communities playing a critical role to its success. It also requires the ready availability of information to the stakeholders, especially the community members. The study found that the implementation process was not well-marketed in the communities and that most of the people were not familiar with the CHPS programme. Such failure of exposure of the programme affected its patronage by the community members. This finding is supported by other studies, which found that awareness creation on the implementation of community health programmes is important to their success (Tum et al. 2013; Bua et al. 2015; Tilley-Gyado et al. 2016). This finding could be due to inadequate information dissemination about the programme or the inadequate use of electronic and social media platforms in the marketing of the programme (Lingard et al. 2012). It could also be due to the fact that the traditional authorities were not involved in the marketing of the programme. Traditional leaders are good at community mobilization and they are trusted by their communities, therefore, messages coming from them are more likely to be taken seriously (Assanful 2018). The finding suggests that the district assembly leadership needs to intensify public education on the CHPS programme and increase the number of CHPS service centres in the communities in order to increase awareness, access and utilization of CHPS services in the communities. 
The study found poor adherence to the implementation steps and this is supported by other studies on the CHPS implementation process (Nyonator et al. 2005; Binka et al. 2009; MOH 2016). This lack of fidelity could be due to the complex nature of the implementation steps. The current fifteen (15) CHPS implementation steps and the six (6) milestones look cumbersome, time-consuming and financially challenging. For instance, it takes weeks and a huge financial outlay to plan and successfully carry out a single durbar. The current CHPS policy implementation document includes five such durbars. The poor adherence to the implementation steps could also be due to poor leadership and lack of managerial competence at the district level (Mapetere et al. 2012; Awoonor-Williams et al. 2013). This issue should be addressed through further and regular training of the district officers handling the implementation processes.

The study found that the traditional authorities were not given any specific role to play in the implementation processes. This finds credence in other studies that found that CHPS compounds have been constructed in sacred groves and rubbish dump sites in Ghana; a situation that is unlikely to happen if the traditional authorities had been actively engaged in the implementation processes (Binka et al. 2009; MOH 2012). There are defined roles for the chiefs in the policy implementation process in which they are to organise durbars and select community health volunteers (CHVs) and community health management committee (CHMC) members. It appears that the chiefs and the traditional leaders, aside selecting the health volunteers and the health committee members, do not play any active role in the implementation process. This could mean that the traditional authorities lack the understanding that for the programme to be sustained, they need to put in place measures to ensure that the selected volunteers performed their duties. 
The study revealed that the traditional authorities expected to be given assigned roles by the district assembly leadership in order to perform other roles in the programme because they did not want to be seen as usurping the powers of the state. The nonspecific involvement of the traditional authorities could be due to the perennial conflict that exists between traditional authorities and state functionaries (Inkoom et al. 2004). Since the advent of the local government system in Ghana, studies have found that traditional authorities have been politically, administratively and financially marginalised (Kessey 2006; Mahama 2009). Other studies have shown that in Ghana, interactions between local government units and traditional authorities are characterised by mistrust generated by competition for power and legitimacy, which tend to stifle genuine participation between the two systems of government at the district level (Taabazuing et al. 2013). This finds corroboration in a study that looked at the role of the chieftaincy institution in the attainment of the Sustainable Development Goals (SDGs) in Ghana, which concluded that successful implementation of the SDGs would be faster if the chiefs are actively involved in the process and given specific roles to play (Assanful 2018). The willingness to collaborate in the implementation of programmes at the district level should be actively promoted by the state (Trivellato et al. 2014).

The study found that the community members participated satisfactorily in the implementation process. This is supported by a study on CHPS carried out in the Upper East region of Ghana (Sakeah et al. 2014). Active community participation is the key to the successful implementation, management and sustainability of the CHPS programme (Nyonator et al. 2006; Binka et al. 2009; Awoonor-Williams et al. 2013). 
However, in this study, a significant number of the community members (30\%) were not actively involved in the implementation process. Other studies have shown that inadequate community participation leads to a stunting of community health programmes and hampers their successful scale-up (Kuyini et al. 2011; Marston et al. 2013). The high level of non-participation in the implementation process, found in this study, should be a wake-up call that needs to be urgently addressed. The nonparticipation could be attributed to lack of awareness of the programme among the community members and poor communication and information sharing between the implementing agency and the community (Kilewo et al. 2015). Being the social and spiritual leaders of the people, the chiefs should be given specific roles to play in mobilizing the people behind the CHPS programme because the people are more likely to listen to and obey them (Assanful 2018).

This study found that the district assemblies enjoy a lot of support for their CHPS activities. The study, however, revealed that the main issue affecting the successful scale-up of the programme is the numerous chieftaincy disputes within the communities. It was found that the district authorities tended to by-pass communities with chieftaincy disputes when allocating CHPS zones. This assertion finds credence in the finding that although the Ga West district has about one hundred and ninety-three (193) settlement communities, the Ga West municipal assembly has only been able to inaugurate thirty-five (35) CHPS zones as at the end of 2017. On the other hand, the Ga East district, which is about three-fold smaller than Ga West has thirty-seven (37) CHPS zones. This implies that the CHPS zones are demarcated selectively within the districts because of chieftaincy disputes. Chieftaincy disputes could therefore be the main reason behind the inability of the CHPS programme to be scaled-up as they tended 
to impede the community entry processes. This finding is supported by other studies that have underscored the deleterious effects of chieftaincy conflicts on the implementation of development programmes in local communities (Boafo-Arthur 2003; Abotchie 2006; Anantatmula 2008; Asamoah 2012).

The few respondents who thought the district assembly leadership could have done better suggested that they should have engaged other stakeholders in the communities in rolling out the programme. For instance, in places where no substantive chief could be found, some suggested that the assembly could have fallen on such opinion leaders as the resident assembly member, retired teachers, retired nurses or religious leaders in those communities to help with the implementation processes. This is supported by an Indonesian study, which found that the village head ceased to be the sole authority under the advent of decentralization (Antlöv 2010).

\section{Conclusions and recommendations}

In this study, it has been shown statistically that the CHPS policy implementation processes were not flawed. However, the main reason for the inability of the programme to be scaled-up is the numerous chieftaincy disputes within the communities, which are hampering the community entry processes of the policy. The study also found that fidelity to the CHPS policy implementation steps is challenging because the steps are cumbersome and should be simplified. Furthermore, the study revealed that the implementation of the CHPS programme could be successfully carried out by the inclusion of other leadership groups in the community entry process beside the chiefs. 
These findings call for a collaborative effort between the policy makers, the Ministry of Health and the allied ministries, notably, the Ministry of Local Government and Rural Development and the Ministry of Chieftaincy Affairs to work together to ensure the successful scaling-up and sustainability of the CHPS programme in Ghana.

\section{Competing interests}

We, the authors, declare that we have no financial or non-financial competing interests in this research.

\section{REFERENCES}

1. World Health Organization (WHO), 2013. The World Health Report 2013: Research for universal health coverage. World Health Organization Press. August. P: 146

2. World Health Organization (WHO), 2008. World Health Report 2008. Primary Health Care: Now more than ever. World Health Organization Press. Geneva.

3. Adongo, P. B., Phillips, J., Aikins, M., Arhin, D., Schmitt, M., Nwameme, A., Tabong, P. \& Binka, F., 2014. Does the design and implementation of proven innovations for delivering basic primary health care services in rural communities fit the urban setting: The case of Ghana's Community-based Health Planning and Services (CHPS). Journal of Health Research Policy and Systems. Vol. 12 (16).

4. Abiiro, G. A. \& De Allegri, M., 2015. Universal health coverage from multiple perspectives: A synthesis of conceptual literature and global debates. BMC Journal of International Health \& Human Rights. Vol. 15 (17). 
5. Binka, F. N., Aikins, M., Sackey, O. S., Aryeetey, R., Dzodzomenyo, M., Esena, R., Adongo, P. B., Akweongo, P. \& Opoku-Mensah, K., 2009. In-depth review of the Community-Based Health Planning and Services (CHPS) Programme. A report of the MOH Annual Health Sector Review. (April 2009)

6. Krumholz, A. R., Stone, A. E., Dalaba, M. A., Phillips, J. F. \& Adongo, P. B., 2014. Factors facilitating and constraining the scaling-up of an evidence-based strategy of community-based primary care: Management perspectives from northern Ghana. Journal of Global Public Health. http://dx.doi,org/10.1080/.

Organizational Dynamics. Vol. 35 (1). Pp: 12-31.

7. Pienaar, L., 2016. Investigating the reasons behind the increase in medical negligence claims. PER/PELJ. Vol (19).

8. McCormack, L. A., Jones, S. G. \& Coulter, S. L., 2017. Demographic factors influencing non-urgent emergency dependent utilization among a Medicaid population. Health Care Management Science. Vol 20 (3). Pp: 395-402.

9. Ghana Statistical Service (GSS), 2014. 2010 Population \& housing census: Ga East and West Municipal District Analytical Report.

10. Mahama, C., 2009. Local government and traditional authorities in Ghana: towards a more productive relationship. Commonwealth Jo of local governance. Vol.4

11. Tum, S. J., Maree, J.E. \& Clarke, M., 2013. Creating awareness and facilitating cervical and breast cancer screening uptake through the use of a community health worker: A pilot intervention study. European Journal of Cancer Care. Vol (22). Pp.: 107-116 
12. Bua, J., Paina, L. \& Kiracho, E. E., 2015. Lessons learnt during the process of setup and implementation of the voucher scheme in Eastern Uganda: a mixed methods study. Journal of Implementation Science. Vol (10): 108

13. Tilley-Gyado, R., Filani, O., Morhason-Bello, I. \& Adewole, I. F., 2016. Strengthening the primary care delivery system: A catalytic investment toward achieving universal health coverage in Nigeria. Journal of Health Systems \& Reform. Vol. 2(4).

14. Lingard, H., Francis, V. \& Turner, M., 2012. Work-life strategies in the Australian construction industry: Implementation issues in a dynamic projectbased work environment. International Journal of Project Management. Vol. 30(3). Pp: 282-295.

15. Assanful, V., 2018. Chieftaincy and the attainment of Sustainable Development Goal 16: The role of the Akan chief. https://www.researchgate.net/publication/326834838.

16. Ministry of Health (MOH), 2016. Ghana National CHPS Policy Document.

17. Mapetere, D., Mavhiki, S., Tonderai, N., Sikomwe, S. \& Mhonde, C., 2012. Strategic role of leadership in strategy implementation in Zimbabwe's stateowned enterprises. International Journal of Business and Social Science. Vol. 3(16). Pp: 271-276.

18. Awoonor-Williams, J. K., Sory, E. K., Nyonator, F. K., Phillips, J. F., Wang, C. \& Schmitt, M. L., 2013. Lessons learned from scaling up a community-based health programme in the Upper East Region of northern Ghana. Journal of Global Health: Science and Practice. Vol. 1(1). Pp: 119-133;

19. Ministry of Health (MOH), 2012. Brief on status of CHPS implementation. 
20. Inkoom, D.K.B. \& Post, J., 2004. Social capital, local networks and community action: Experiences with services upgrading in Kumasi, Ghana. International Development Planning Review 26(3):325-350. DOI: 10.3828/idpr.26.3.5.

21. Asamoah, K., 2012. A qualitative study of chieftaincy and local government in Ghana. Journal of African Studies and Development. Vol. 4(3). Pp: 90-95

22. Taabazuing, J., Armah, F., Dixon, J. \& Luginaah, I., 2013. The relationship between traditional authorities and decentralized structures in Ghana: Conflicting roles or a struggle for power and legitimacy. International Journal of Development and Conflict. Vol 2 (3). Pp: 1-25

23. Trivellato, B., Boselli, R. \& Cavenago, D., 2014. Design and implementation of open-government initiatives at the sub-national level: lessons from Italian cases. Journal of Open Government. Vol 4. Pp: 65-84

24. Sakeah, E., McCloskey, L., Bernstein, J., Yeboah-Antwi, K., Mills, S. \& Doctor, H.V., 2014. Is there any role for community involvement in the community-based health planning and services skilled delivery programme in rural Ghana? BMC Health Services Research Journal. Vol. 14 (340).

25. Baatiema, L., Skovdal, M., Rifkin, S. \& Campbell, C., 2013. Assessing participation in a community-based health planning and services programme in Ghana. BMC Journal of Health Services Research. 13:233.

26. Marston, C., Renedo, A., McGowan, C.R. \& Portela, A., 2013. Effects of community participation on improving uptake of skilled care for maternal and newborn health: A systematic review. PLoS ONE Journal. Vol. 8 (2): e55012.

27. Kilewo, E. G. \& Frumence, G., 2015. Factors that hinder community participation in developing and implementing comprehensive council health 
plans in Manyoni District, Tanzania. Global Health Action Journal. Vol. 8. 26461

28. Boafo-Arthur, K., 2003. Chieftaincy in Ghana: Challenges and prospects in the $21^{\text {st }}$ Century. Journal of African and Asian Studies. Vol. 2. Pp: 125-153

29. Abotchie, C., 2006. Has the position of the chief become anachronistic in the contemporary Ghanaian politics? Journal of Culture, Governance and Development. Pp.: 169-182

30. Anantatmula, V., 2008. The role of technology in project manager performance. Project Management Journal. Vol. 39(1). Pp: 34-48.

31. Antlöv H., 2010. Village government and rural development in Indonesia: the new democratic framework. Bulletin of Indonesian Econ Studies. Vol. 39 (2).

\section{APPENDIX: CHPS Policy Implementation Steps and Milestones}

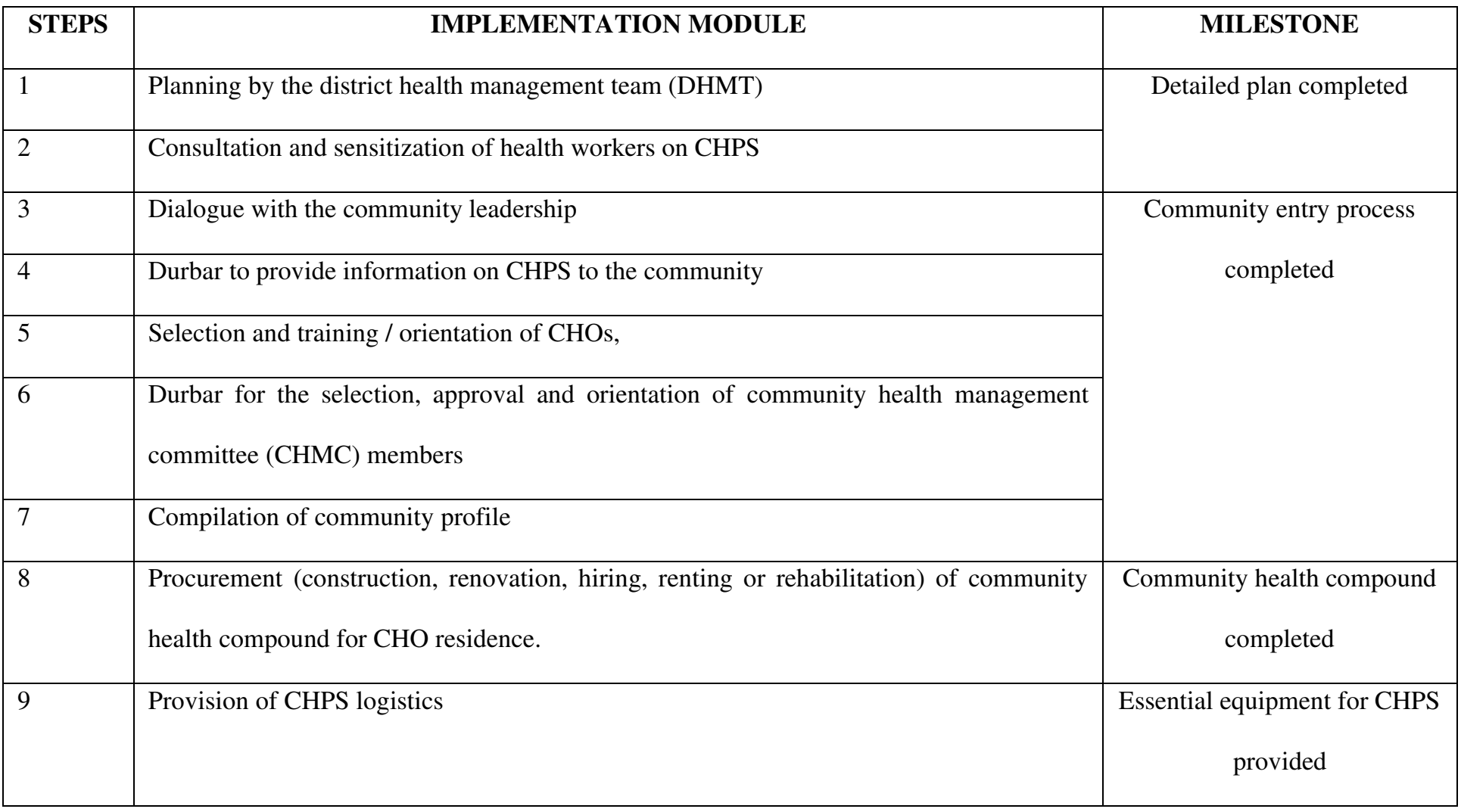




\begin{tabular}{|l|l|c|}
\hline 10 & Durbar to launch activities of the CHPS zone & CHO posted to site \\
\hline 11 & Selection of community health volunteers (CHVs) & CHVs deployed \\
\hline 12 & Durbar to finalize the selection and approval of CHVs & \\
\hline 13 & Training of community health volunteers & \\
\hline 15 & Durbar to launch the CHPS zone: & \\
\hline
\end{tabular}

Source: Ministry of Health (Ghana): National CHPS Policy Document, 2016. 


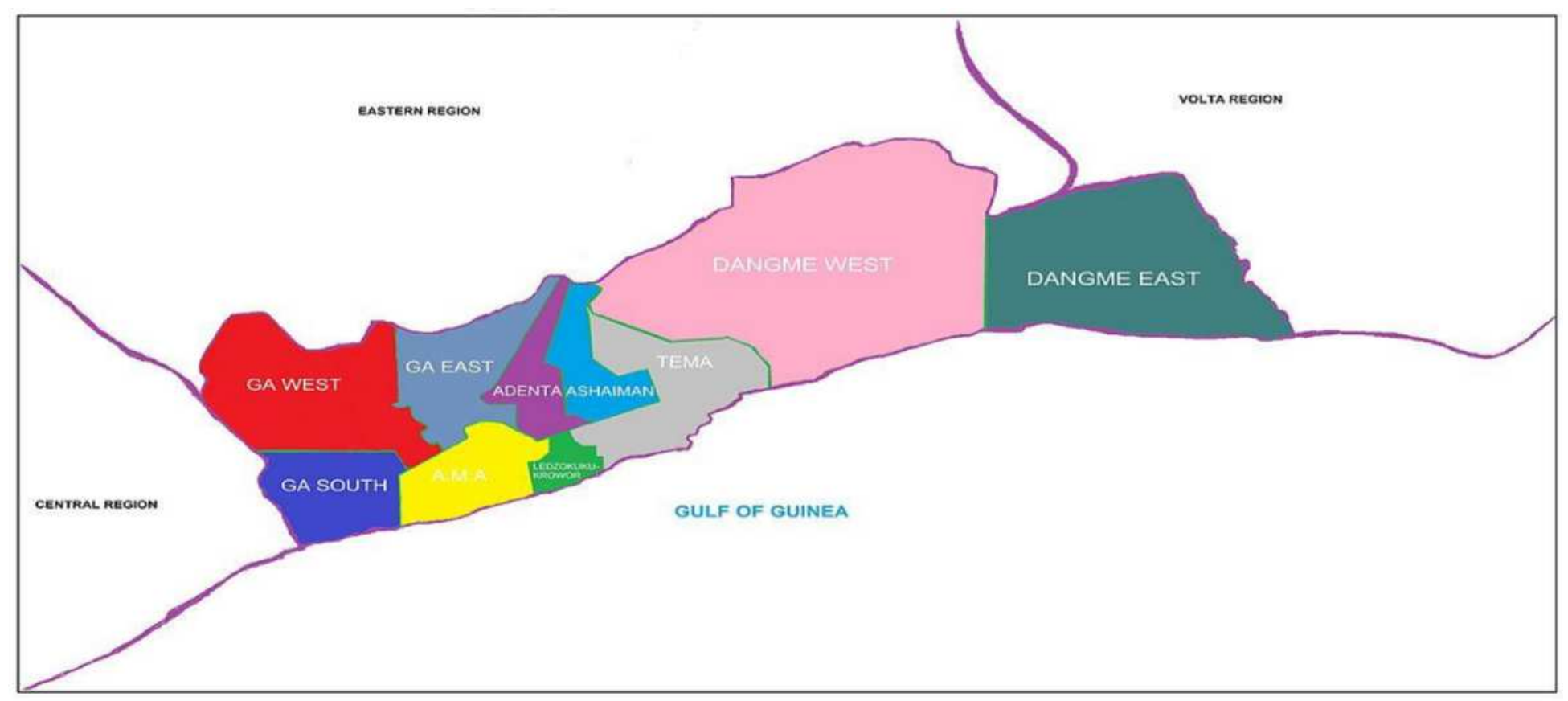

Figure 1

Districts in the Greater Accra Region showing locations of Ga East and Ga West Source: www.ghanadistricts.com (Retrieved on 5th March 2018) Note: The designations employed and the presentation of the material on this map do not imply the expression of any opinion whatsoever on the part of Research Square concerning the legal status of any country, territory, city or area or of its authorities, or concerning the delimitation of its frontiers or boundaries. This map has been provided by the authors. 


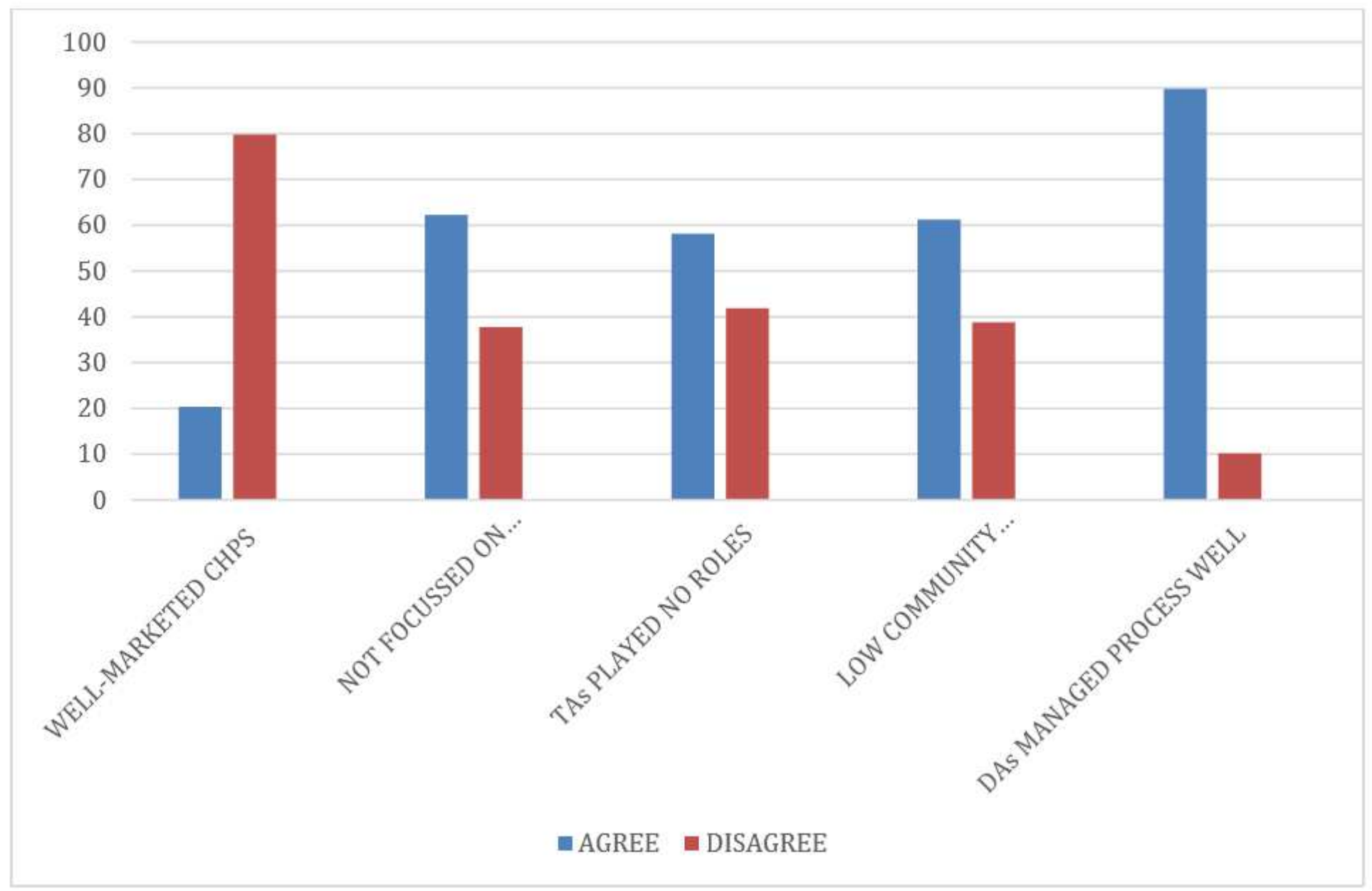

Figure 2

Responses to the CHPS policy implementation processes 